\title{
Annual monitoring of soil radon behavior and entry into building
}

\author{
Andrey Tsapalov' and Konstantin Kovler'* \\ 'National Building Research Institute, Faculty of Civil and Environmental Engineering, Technion - Israel Institute of \\ Technology, Haifa, Israel
}

\begin{abstract}
A simple experimental scheme is proposed to study the concentration behavior and mechanism of soil radon transport from beneath a building foundation. In addition to the results of the annual monitoring of soil radon concentration and environmental factors, the calculated results of the annual continuous monitoring of the soil radon entry rate into experimental room with high levels of indoor radon are presented. This room is located in the basement of one of the buildings in Haifa, Israel. The correlation between radon behavior and environmental factors is discussed. It is found that the soil radon concentration beneath the building is maximum in the winter season due to very heavy rains. There is an absence of soil radon entry by only convection mechanism into the experimental room for the summer and autumn seasons; however, the indoor radon concentration remains high (about $500 \mathrm{~Bq} \mathrm{~m}^{-3}$ ) due to diffusion of soil radon. A regular soil radon entry into the experimental room by convection is observed in the winter and spring seasons with a maximum, approximately at the beginning of the spring season, and therefore, the indoor radon concentration is twice as high as in the summer and autumn seasons. The obtained results indicate that not only convective process but also diffusion of soil radon plays a significant role in the formation of indoor radon.
\end{abstract}

Keywords: soil radon; indoor radon; concentration; radon entry rate; diffusion; convection; monitoring

$\mathrm{R}$ adon is a dangerous carcinogen (1) constituting $3-14 \%$ of lung cancer, as stated by the World Health Organization (WHO) (2). Indoor radon is the main source of human exposure to radiation because about $80 \%$ of our life-time is spent inside buildings. According to the recommendations of WHO (3) and Basic Safety Standards (BSS) Directive (4), the annual average indoor radon (AAIR) concentration should be limited to $300 \mathrm{~Bq} \mathrm{~m}^{-3}$. The national reference levels (RLs) of indoor radon vary in different countries due to differences in regional levels and usually range from 100 to $300 \mathrm{~Bq} \mathrm{~m}^{-3}$.

Radon is formed as a result of the natural decay of ${ }^{226} \mathrm{Ra}$, a part of the 'uranium-radium' family of radionuclides that are unevenly distributed in the crust of the earth (5). Possessing neither color nor odor, radon is a noble gas, and therefore, can migrate intensively in porous media (as soil) due to molecular diffusion, as well as gas convection. The main source of radon in buildings is soil (5). The flow of soil radon into the atmosphere or into buildings can vary significantly in space and time. This depends on geological, climatic, and weather conditions (6), as well as on the construction of the building foundation and connections of engineering utilities. In contrast to the atmosphere, radon can be accumulated inside building; however, its long-term accumulation is normally prevented by natural or forced ventilation.

The behavior of indoor radon is the result of the two competing and very unstable anthropogenic phenomena: air change and radon entry. Both air change rate (ACR) and radon entry rate (RER) should be considered when designing the buildings, especially in radon priority areas. ACR is an important hygienic parameter that is regulated by building codes and must be ensured at the minimum level through appropriate design decisions (7), considering the particular climate. If the Reference Level (RL) for indoor radon and ACR is known, then using the well-known indoor radon balance equation (5), one can estimate the maximum allowable RER level at which the AAIR concentration will not be exceeded. However, the question arises on how to ensure the calculated (control) RER level is not exceeded using data on the geology (related to soil radon), structure, and materials of the building foundation. For example, in the study by Gulabyants et al. (8), a completely adequate physical algorithm and a solution to this problem are given, which, however, assumes that diffusion is the main process for transport of soil radon into building. At the same time, many scientific reports $(9,10)$ argue 
that the decisive transport of soil radon into building is by convection due to the so-called 'stack effect' (11), although neither single experimental scheme nor experimental data on RER to prove it have been presented so far. Indeed, there are many publications that provide compelling indirect and model evidence that soil gas convection is responsible for high levels of indoor radon but are we completely sure that there are no buildings in which diffusive transport prevails over the soil radon convection?

In addition, the lack of direct control over ACR due to its complexity $(12,13)$ does not allow making accurate conclusions about the amplitude (specific values) and temporal variations of RER based only on the results of measurements of indoor radon concentration. In this regard, it is important to develop experimental schemes that allow direct measurements of RER, or at least estimate the magnitudes of parameters, which are closely related to RER.

In contrast to diffusion, the extremely irregular action of convection significantly complicates the behavior of RER, and consequently a creation of an adequate physical model for accurate estimation and reliable control of RER $(14,15)$. Therefore, when creating mathematical models for the radon transport into building, it would be very important to determine the criteria that allow identifying the mechanism of this transport. Thus, the main goal of this work was to study the patterns of soil radon behavior beneath the building foundation and to define the mechanism of soil radon entry into building using the example of a building with a high concentration of radon in the basement.

\section{Research object, methods, and equipment}

\section{Research object and parameters}

Achieving the above goal, first, requires long-term and continuous data collection (at least for 1 year) in relation to the following three main parameters: 1) soil radon concentration beneath the building foundation, 2) soil RER into the building, and 3) radon concentration indoors. Obviously, the organization of monitoring of 1) and 2) requires drilling the building foundation. In addition, the levels of 1) and 3) should be significantly higher than the background levels to ensure satisfactory accuracy of the raw data to be analyzed. Therefore, one of the basement laboratory rooms in the building of the National Building Research Institute (NBRI) located at the campus of the Technion - Israel Institute of Technology (Haifa) was chosen as a research object (see Table 1), where the natural indoor radon concentration, on average, exceeds $500 \mathrm{~Bq} \mathrm{~m}^{-3}$ (while radon concentrations in the neighbor room are by- two to three times
Table 1. Characteristics of the experimental room and building

\begin{tabular}{|c|c|c|c|}
\hline & \multicolumn{2}{|c|}{ Code } & ERI \\
\hline \multirow{9}{*}{ Room } & \multicolumn{2}{|l|}{ AAIR level, $\mathrm{Bq} \cdot \mathrm{m}^{-3}$} & 722 \\
\hline & \multicolumn{2}{|c|}{ Average temperature (range), ${ }^{\circ} \mathrm{C}$} & $22.5(20-32)$ \\
\hline & \multicolumn{2}{|c|}{ Average humidity (range), \% } & $47(19-65)$ \\
\hline & \multicolumn{2}{|l|}{ Floor } & Basement \\
\hline & \multicolumn{2}{|c|}{ Type of room (number) } & Lab (108) \\
\hline & \multicolumn{2}{|l|}{ Occupancy } & Rarely \\
\hline & \multirow[t]{2}{*}{ Local system of } & $\begin{array}{l}\text { Heating } \\
\text { air conditioning }\end{array}$ & Yes \\
\hline & & Ventilation & Natural \\
\hline & \multicolumn{2}{|l|}{ Room area* } & Middle \\
\hline \multirow{16}{*}{ Building } & \multicolumn{2}{|l|}{ Location } & Technion, Haifa \\
\hline & \multicolumn{2}{|l|}{ Name } & NBRI \\
\hline & \multicolumn{2}{|l|}{ Function } & Office \\
\hline & \multicolumn{2}{|l|}{ Year built } & 1970 s \\
\hline & \multicolumn{2}{|l|}{ Number of stories } & 3 \\
\hline & \multicolumn{2}{|l|}{ Material of walls } & Concrete \\
\hline & \multicolumn{2}{|l|}{ Material of floors } & Concrete \\
\hline & \multirow{3}{*}{ Central system of } & Heating & No \\
\hline & & air conditioning & No \\
\hline & & Ventilation & Natural \\
\hline & \multicolumn{2}{|l|}{ Building area** } & Large \\
\hline & \multicolumn{2}{|c|}{ Asphalt pavement $* * * *$} & Yes \\
\hline & \multicolumn{2}{|l|}{ Foundation type } & Slab \\
\hline & \multicolumn{2}{|l|}{ Basement } & Yes \\
\hline & \multirow{2}{*}{ Geology } & Relief & Uneven \\
\hline & & Soil type & Rocky \\
\hline
\end{tabular}

*Room area: small (area $\left.<20 \mathrm{~m}^{2}\right)$, middle $\left(20 \mathrm{~m}^{2}<\right.$ area $\left.<60 \mathrm{~m}^{2}\right)$, and large (area $>60 \mathrm{~m}^{2}$ ).

**B Building area: small (area $\left.<200 \mathrm{~m}^{2}\right)$, middle $\left(200 \mathrm{~m}^{2}<\right.$ area $\left.<600 \mathrm{~m}^{2}\right)$, and large (area $>600 \mathrm{~m}^{2}$ ).

***The asphalt or other poorly permeable layers surrounding the building.

lower). This experimental room (ER1) has a middle size of $6.0 \times 5.2 \times 3.1 \mathrm{~h} \mathrm{~m}\left(V=96.7 \mathrm{~m}^{3}\right.$ and $\left.S=31.2 \mathrm{~m}^{2}\right)$ and is rarely visited (most of the time it is closed). Experimental room ER 1 is constantly air-conditioned to maintain a stable temperature and humidity without forced outside air inflow. The floors and walls of the room are monolithic structures made of concrete with a thickness of about $20 \mathrm{~cm}$. The concrete foundation slab used as a floor and concrete walls in contact with soil have no entrances of any underground facilities and any defects (which can be visually observed - such as cracks, voids, and openings). The properties of the underlying soil, which obviously serves as a radon source, were not studied because this task was out of the scope of the current project and also because of the difficulty in extracting a sufficient amount of the soil from beneath the foundation slab and from different depths for the analysis. At the same time, it was clear that the main 
composition of the underlying soil represents mainly carbonate rock containing a relatively minor amount of the quartz sand in its upper part used as a construction fill.

The general measurement scheme in ER1, including the location of the soil radon monitoring points, is shown in Fig. 1.

The space behind the wall is only partially filled with soil, the level of which is approximately $1 \mathrm{~m}$ higher than the floor in the basement. Access to this space is not provided; however, it is known that its area in the horizontal section is larger than the floor area of ER1. In the most distant (from the wall of ER1) part of this space, there is a small opening that communicates with the outside air.

Figure 1 shows the location of two sampling points in the floor (FR and FL) and one in the wall (W). The sampling point is a through hole drilled in the structure from which a tube (about $1-\mathrm{m}$ long and with $4 \mathrm{~mm}$ inner diameter) comes into the basement room (ER1). The other end of the tube connects to the small plastic box where the radon monitor (Radon Eye Plus2 or Sun Nuclear $1028 \mathrm{XP}$ ) is installed. The same tube (outlet) comes out from the opposite side of the box, but is much shorter - only $5 \mathrm{~cm}$ long. This scheme was used for continuous measurements of the RER at each of the three measurement points. The soil radon concentration measurements were carried out periodically in the manual sampling mode described in more detail in the next paragraph, through the long tube, which was disconnected from the box for not longer than $5 \mathrm{~min}$. Periodically, for the measurement of pressure differences between the soil gas and indoor air, before manual sampling of the soil radon, the differential pressure meter Testo 512 (with the measurement range of $0-2$ $\mathrm{hPa}$ and the resolution of $1 \mathrm{~Pa}$ ) was connected to the long tube.

The indoor radon concentration measurements were carried out in the continuous monitoring mode with a recording period of $1 \mathrm{~h}$ using a Radon Eye Plus2 located at a height of about $1.5 \mathrm{~m}$.

To assess the influence of various factors on the behavior of soil radon, the data of synchronous annual monitoring of the following environmental factors were also collected: 1) air temperature, 2) humidity, 3) atmospheric pressure, 4) wind speed, 5) precipitation, 6) insolation (related to cloudiness), 7) tidal forces (Earth's rotation speed or length of day), and 8) seismic activity. The collection of such data does not require much effort. For example, the nearest professional weather station in Tel-Aviv, located about $100 \mathrm{~km}$ from the Haifa, served as a source of meteorological data (http://www.rp5.ru). The data on the tidal forces were taken from The International Earth Rotation and Reference Systems Service (http://www.iers. org). The data on seismic activity in the Haifa area with a radius of about $150-200 \mathrm{~km}$ were taken from The Geological Survey of Israel (http://www.earthquake.co.il). In addition, several of the most sensitive earthquakes

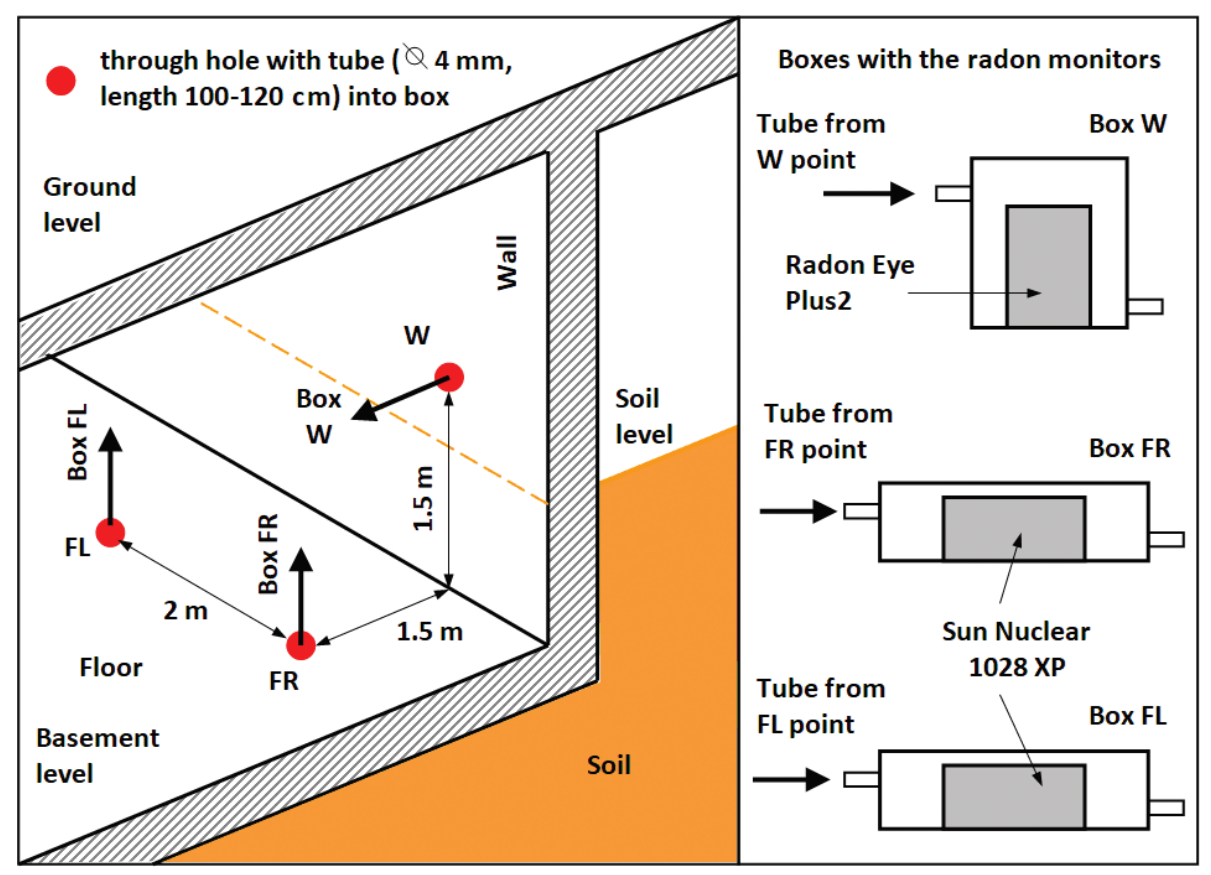

Fig. 1. Scheme of the soil radon measurement in the ER1 located in the basement. 
(with a magnitude of more than 4), which occurred at a greater distance from Haifa, were considered.

\section{Measurement methods}

To avoid the influence of the measurement method on the behavior of soil radon, it was decided to sample the minimum volumes of soil gas only twice a week in manual mode, because the soil radon concentration under the building is more stable than indoor radon. The soil gas was sampled from the FL $(450 \mathrm{~mL}), \mathrm{FR}(450 \mathrm{~mL})$ and $\mathrm{W}$ $(1,050 \mathrm{~mL})$ points periodically, using a simple original sampler including a syringe and the sorption column (SC13) containing activated charcoal (13 mL) (Fig. 2). The SC-13 is capable of adsorbing $100 \%$ of the radon activity of the soil gas sample of a small volume $(<1 \mathrm{~L})$, even at its maximum moisture content (16).

The concentration of soil radon $C_{S}\left(\mathrm{~Bq} \mathrm{~m}^{-3}\right)$ is as follows:

$$
C_{S}=A / V_{S},
$$

where $V_{S}$ is the sample volume $\left(\mathrm{m}^{3}\right)$ and $A$ is radon activity in charcoal at the time of sampling $(\mathrm{Bq})$.

Radon activity in charcoal was measured using a simple but sensitive detector BDB-13, the description and characteristics of which were discussed by Tsapalov (17). This detector was calibrated using a gamma spectrometer and a fine granular non-emanating sample with a known (certified) specific ${ }^{226} \mathrm{Ra}$ activity.

The radon concentration in the boxes to determine the soil RERs into the boxes were continuously measured at the same points FR, FL, and W (Fig. 1). The continuous radon monitor was located inside the box. Two tubes stem from the box on the opposite sides, one of which was short with an open end, and the other tube (long) was connected to the hole drilled in the concrete floor (or wall). If a convective flow of soil radon occurs through a long tube (while the long tube excludes a diffusion flow into the box), the radon activity concentration in the box increases. However, the increase in radon activity in the box is compensated for by the runoff of radon, which is caused by its natural decay, leakage, and convection of soil gas through the short tube. Thus, the balance of radon activity concentrations in the box $C(t)\left(\mathrm{Bq} \mathrm{m}^{-3}\right)$ is approximately described by the following equation:

$$
\frac{C(t+\Delta t)-C(t)}{\Delta t}=\frac{E(t)}{V}-\left[\lambda_{R}+\lambda_{L}+\lambda_{G}(t)\right] \cdot C(t)
$$

where $E(t)$ is the soil RER from the hole in the floor into the box only due to convection $(\mathrm{Bq} / \mathrm{h}), \Delta t$ is the registration period of radon concentration in the box equal to $1 \mathrm{~h}, V$ is the box free volume, which is equal to $0.0035 \mathrm{~m}^{3}$ with the installed Sun Nuclear 1028 XP continuous radon monitor, or to $0.0030 \mathrm{~m}^{3}$ for the box containing Radon Eye Plus 2 device, $\lambda_{R}$ is the radon decay constant $(0.00755$ $1 / \mathrm{h}), \lambda_{L}$ is the radon leakage $(1 / \mathrm{h})$, and $\lambda_{G}(t)$ is the soil gas change rate in the box $(1 / \mathrm{h})$.

In the case of estimating the rate of radon flux in the opposite direction (from the air of the room to the soil), equation (2) is not entirely correct. Nevertheless, extremely low and negative values of $E(t)$ will qualitatively indicate the absence of soil radon entry into room by convection or the existence of a reverse flux. In addition, a quantitative assessment of the reverse radon flux is not of interest in the framework of this study.

The parameter $\lambda_{G}(t)$ is related to the volumetric rate $W(t)\left(\mathrm{m}^{3} / \mathrm{h}\right)$ of the convective flux of soil radon, which enters the box with the know volume $V$ through the long tube:

$$
\lambda_{G}(t)=\frac{W(t)}{V}
$$

At the same time, $W(t)$ is related to $E(t)$ and to the current soil radon concentration:

$$
W(t)=\frac{E(t)}{C_{S}(t)}
$$

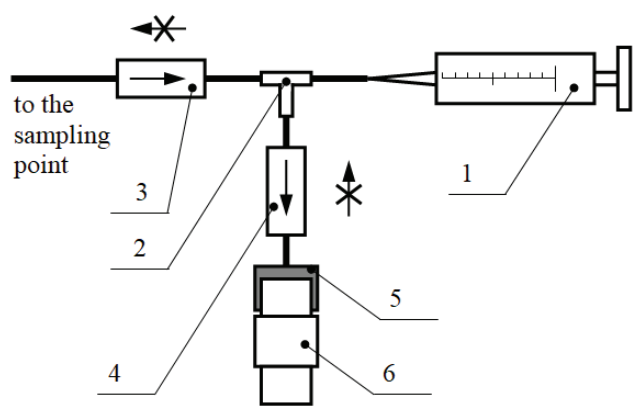

1 - syringe with a volume of $150 \mathrm{~mL}$

2 - wye

3,4 - valves

5 - adapter for connecting the SC-13

6 - SC-13 (sorption column)

Fig. 2. Equipment for manual sampling of soil radon on the column with activated charcoal. 
Thus, the equilibrium equation (2) can be rewritten as follows:

$$
\frac{C(t+\Delta t)-C(t)}{\Delta t}=\frac{E(t)}{V}-\left[\lambda_{R}+\lambda_{L}+\frac{E(t)}{V \cdot C_{S}(t)}\right] \cdot C(t)
$$

The value of the radon leakage from the box is determined using the following simple experiment. The high activity of radon is injected inside the box, and the long tube is closed. Then, a decrease in the radon concentration in the box is recorded until it drops down to $2,000 \mathrm{~Bq} \mathrm{~m}^{-3}$ in the continuous measurement mode. The combined value of radon decay constant and leakage from the box $\left(\lambda_{R}+\lambda_{L}\right)=0.0341 / \mathrm{h}$ is the result of the calculation according to formula (2), where $E(t)=0$ and $\lambda_{G}(t)=0$. Then the time series of the measured values of radon concentration in the box can be transformed into the time series of the values of $E(t)$ using the following expression derived from Equation 5:

$$
E(t)=\frac{V}{1-C(t) / C_{S}(t)} \cdot\left[\frac{C(t+\Delta t)-C(t)}{\Delta t}+0.034 \cdot C(t)\right]
$$

The results of the radon activity concentration measured by different continuous monitors and using the charcoal method in the corresponding ranges were compared. Testing has shown a good convergence of measurement results over a concentration range of $100-10,000 \mathrm{~Bq} \mathrm{~m}^{-3}$. However, in the higher range Sun Nuclear 1028 XP underestimated the radon concentration relatively to the charcoal method (see above), which is the reference method. Figure 3 shows the experimental points

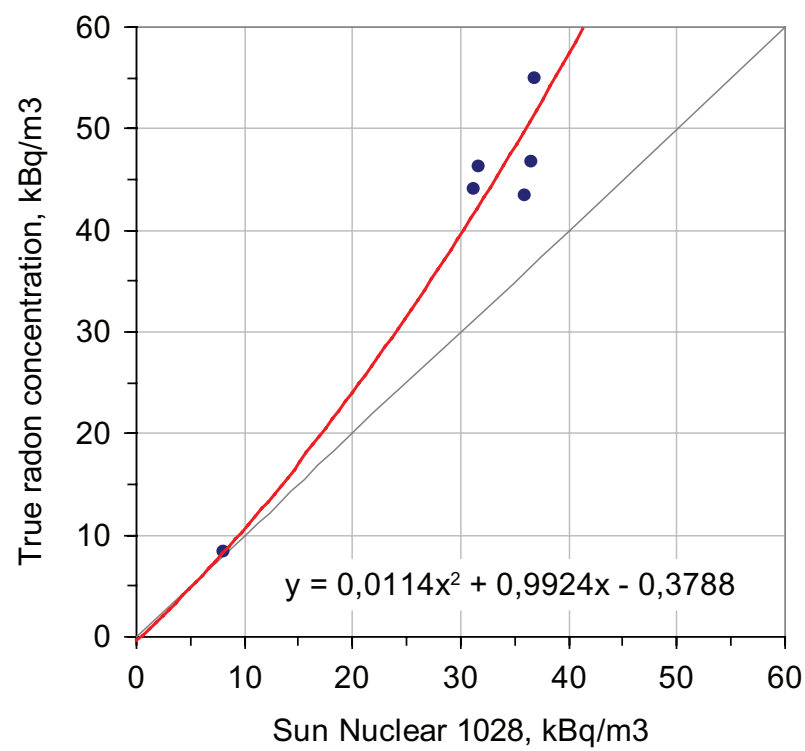

Fig. 3. Correction function for measurement results by Sun Nuclear 1028 XP. of simultaneous measurements of radon concentration by the Sun Nuclear 1028 XP and the charcoal method, and also provides the correction function to reconstruct the true radon concentration from the measurement results by Sun Nuclear 1028 XP. The results of the radon concentration measurements by Sun Nuclear 1028 XP multiplied by the correction function value represent the 'true radon concentrations'.

Results

The continuous measurements of indoor radon and radon concentrations in the boxes FR and $\mathrm{W}$ were conducted since 12 July, 2019, and the periodical measurements of soil radon concentration in the points FL, FR, and W since 24 October 2019. A bit later, at 01 November 2019 the parallel continuous measurements of radon concentrations in the box FL started. Unfortunately, due to the lockdown of the lab activities caused by the Coronavirus pandemic, the annual monitoring of soil radon concentration is not complete; nevertheless, this practically did not worsen the quality of the experimental observations and the corresponding conclusions.

The results of the annual continuous monitoring of radon concentrations and various environmental factors are shown in Fig. 4.

As can be seen from Fig. 4, hot weather characterizes the summer season with an average temperature of $25-30^{\circ} \mathrm{C}$, without any precipitation, and with an average wind speed of $3-5 \mathrm{~m} / \mathrm{s}$. For the winter season, the average temperature was about $15-20^{\circ} \mathrm{C}$, with strong gusts of wind being more frequently observed at a slightly higher average speed, in parallel with heavy rainfalls in the form of tropical showers. For this reason, in the winter season, the moisture content of the soil beneath the buildings increased; so on 26 December 2019, it was already impossible to sample a soil gas at the FR point. After the next very heavy rain on 04 January 2019, rainwater penetrated into some of the basements, including ER1. The soil under the foundation of the building became saturated with moisture; therefore, between 05 and 12 January it was impossible to conduct measurements and, accordingly, to determine the concentration of soil radon in the both FR and FL points by manual sampling. The next missing soil radon measurements from 15 March 2015 to 26 April 2020 was due to the strict lockdown of the lab activities caused by the spread of Coronavirus in the country.

The reconstructed results of radon concentration monitoring in the FR and FL boxes using the equation from Fig. 3, including the values of soil RERs into the boxes from the FR and FL points calculated by Equation (6), are shown in Fig. 5. Because the soil radon concentration measurements started after the commencement of the radon concentrations in the box FR, the initial value $C_{S}=50 \mathrm{kBq} \mathrm{m}^{-3}$ was assumed for the calculation of the 

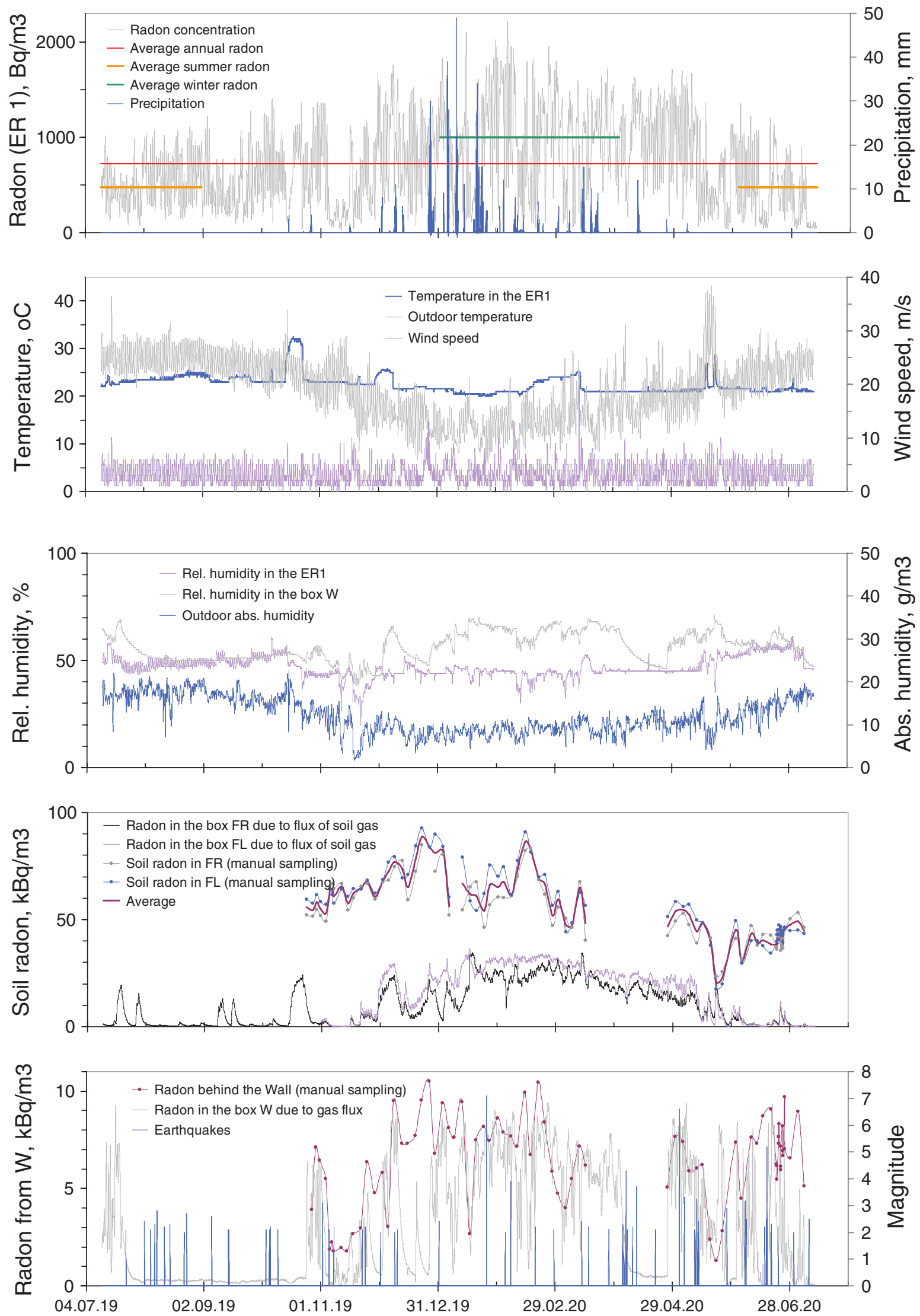

Fig. 4. Results of continuous monitoring of soil and indoor radon concentration in the ER1 and environmental factors. 

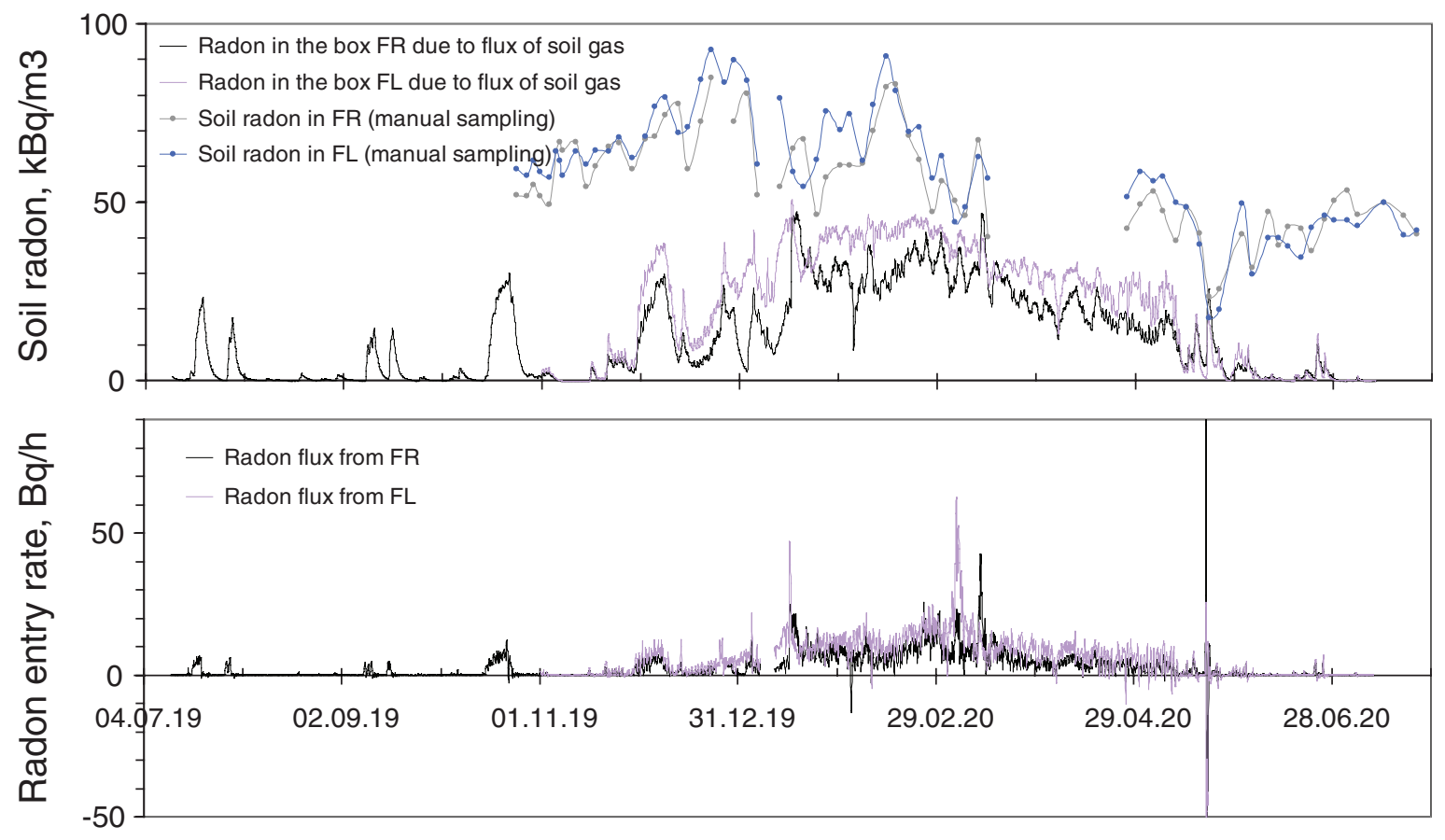

Fig. 5. Reconstructed results of radon concentration monitoring in the FR and FL boxes, and calculated soil RER from the FR and FL points.

RER from the FR point in the beginning of the study. The same value of $C_{S}$ was used for the calculation of RER from the FR and FL points during the lockdown period. The modelling shows that the variations of $C_{S}$ in the range $30-70 \mathrm{kBq} \mathrm{m}^{-3}$ do not significantly affect the changes in the calculated values of the RER corresponding to the two periods mentioned above.

The average soil radon concentrations in the FR and FL points for the entire measurement period from 24 October, 2019 till 23 July, 2020 (excluding the lockdown period) differed insignificantly and were equal to (55.5 \pm $13.6)$ and $(59.1 \pm 16.2) \mathrm{kBq} \mathrm{m}^{-3}$, respectively.

The time series of the calculated values of RER from the $\mathrm{W}$ point is not given in Fig. 5, because their average value for the period 01 November 2019 to 01 July 2020 was only $0.29 \mathrm{~Bq} / \mathrm{h}$. This value is much lower than the RER observed from the FR (4.62 Bq/h) and FL (5.60 $\mathrm{Bq} / \mathrm{h}$ ) points for the same period.

Periodical measurements of the pressure differences between soil gas and indoor air during the year demonstrate that the maximum difference does not exceed $1 \mathrm{~Pa}$ in the FR and FL points and $2 \mathrm{~Pa}$ in the $\mathrm{W}$ point. The maximum values were observed in winter, while in summer the pressure drop fluctuated around zero. The pressure difference of 1-2 $\mathrm{Pa}$ can be hardly determined accurately at the device error of only $1 \mathrm{~Pa}$. However, we assume that there is no need for measuring so accurately such a low-pressure difference.
The obtained continuous time series of radon and environmental factors made it possible to carry out a correlation analysis, the results of which are shown in Table 2.

\section{Discussion}

For more convenient comparison and discussion of the obtained data, the results of the annual monitoring and their trends, as well as the calculated and average values of the most important parameters, are shown in Fig. 6.

Analysis of the data in Figs. 5 and 6, as well as the correlation coefficients in Table 2, leads to the following observations:

1. RERs from the FR and FL points, as well as the soil radon concentrations at these points, are qualitatively similar, and differ slightly quantitatively, which indicates a spatial similarity of the soil radon behavior beneath the building foundation slab within the area of the experimental room ER1. It can be seen that the correlation between the soil radon concentration and entry rate is poor. Besides, soil radon concentration and entry rate are weakly correlated with indoor radon. This can be explained by significant temporal variations in natural ventilation in this experimental room at its low average level, since the ER 1 is in the basement and closed (however, ventilation rate was not measured in this study). 
Table 2. The correlation coefficient between radon and environmental (influencing) factors

\begin{tabular}{|c|c|c|c|c|c|c|c|c|}
\hline \multirow{3}{*}{ Influencing fac } & & & \multirow{3}{*}{$\begin{array}{l}\text { Indoor radon } \\
\text { in the ERI }\end{array}$} & \multicolumn{5}{|c|}{ Soil radon } \\
\hline & ctor & & & \multicolumn{2}{|c|}{$\begin{array}{l}\text { Radon entry rate } \\
\text { from the point (calculated) }\end{array}$} & \multicolumn{3}{|c|}{$\begin{array}{l}\text { Concentration in the point } \\
\text { (manual sampling) }\end{array}$} \\
\hline & & & & $\mathrm{FL}$ & FR & $\mathrm{FL}$ & FR & W \\
\hline \multirow{6}{*}{ Soil radon } & \multirow{3}{*}{ Radon entry } & FL point & 0.28 & - & 0.82 & 0.31 & 0.30 & 0.14 \\
\hline & & FR point & 0.28 & 0.82 & - & 0.38 & 0.36 & 0.25 \\
\hline & & W point & 0.35 & 0.22 & 0.28 & 0.22 & 0.16 & 0.19 \\
\hline & \multirow{3}{*}{ Concentration } & FL point & 0.40 & 0.31 & 0.38 & - & 0.90 & 0.19 \\
\hline & & FR point & 0.29 & 0.30 & 0.36 & 0.90 & - & 0.09 \\
\hline & & $W$ point & 0.46 & 0.14 & 0.25 & 0.19 & 0.09 & - \\
\hline \multirow{4}{*}{ Temperature } & \multicolumn{2}{|l|}{ Outdoor (O) } & -0.65 & -0.37 & -0.35 & $-0.8 I^{(9 h)}$ & $-0.67^{(9 h)}$ & -0.30 \\
\hline & \multicolumn{2}{|l|}{ Indoor (I) } & -0.16 & 0.04 & 0.09 & 0.11 & 0.22 & -0.40 \\
\hline & \multicolumn{2}{|c|}{ Difference: $(\mathrm{I})$ - (O) } & 0.65 & 0.38 & 0.37 & $0.80^{(12 h)}$ & $0.69^{(12 h)}$ & 0.23 \\
\hline & \multicolumn{2}{|l|}{ Dew point } & -0.28 & -0.14 & -0.16 & -0.66 & -0.59 & 0.18 \\
\hline \multirow{2}{*}{ Pressure } & \multicolumn{2}{|l|}{ Sea surface } & 0.40 & 0.25 & 0.13 & $\left.0.7\right|^{(15 h)}$ & $0.54^{(15 h)}$ & 0.11 \\
\hline & \multicolumn{2}{|c|}{ Barometric tendency } & 0.12 & -0.02 & 0.01 & $0.43^{(15 h)}$ & $0.30^{(15 h)}$ & 0.20 \\
\hline \multirow{6}{*}{ Humidity } & \multicolumn{2}{|c|}{ Outdoor relative (OR) } & 0.50 & 0.27 & 0.24 & 0.29 & 0.20 & 0.50 \\
\hline & \multicolumn{2}{|c|}{ Outdoor absolute (OA) } & -0.31 & -0.17 & -0.20 & -0.65 & -0.58 & 0.19 \\
\hline & \multicolumn{2}{|c|}{ Indoor relative (IR) } & -0.17 & -0.16 & -0.17 & $-0.59^{(18 h)}$ & $-0.64^{(18 h)}$ & 0.27 \\
\hline & \multicolumn{2}{|c|}{ Indoor absolute (IA) } & -0.21 & -0.12 & -0.10 & -0.59 & -0.60 & 0.09 \\
\hline & \multicolumn{2}{|c|}{ Difference: (OR) - (IR) } & 0.54 & 0.32 & 0.29 & $0.44^{(15 h)}$ & $0.37^{(15 h)}$ & 0.38 \\
\hline & \multicolumn{2}{|c|}{ Difference: $(\mathrm{OA})$ - (IA) } & -0.29 & -0.14 & -0.19 & -0.60 & -0.51 & 0.19 \\
\hline \multicolumn{3}{|l|}{ Wind speed } & -0.22 & 0.00 & 0.10 & $-0.33^{(15 h)}$ & $-0.40^{(15 h)}$ & $0.22^{(18 h)}$ \\
\hline \multicolumn{3}{|l|}{ Precipitation } & 0.07 & 0.04 & 0.10 & 0.24 & 0.24 & 0.16 \\
\hline \multicolumn{3}{|l|}{ Cloudiness } & 0.23 & 0.20 & 0.26 & $0.35^{(9 h)}$ & $0.25^{(9 h)}$ & $0.34^{(9 h)}$ \\
\hline \multicolumn{3}{|c|}{ Tidal forces (length of day) } & 0.46 & 0.45 & 0.44 & 0.53 & 0.48 & -0.22 \\
\hline \multicolumn{3}{|l|}{ Earthquakes } & 0.02 & -0.02 & -0.02 & -0.10 & -0.14 & 0.19 \\
\hline \multicolumn{9}{|c|}{ Legend: } \\
\hline \multirow{2}{*}{\multicolumn{2}{|c|}{$\begin{array}{l}\text { Range } \\
\text { Correlation }\end{array}$}} & $<0.30$ & 0.30 & 0.45 & 0.4 & & & \\
\hline & & Absent or very weak & W & & Mo & & & \\
\hline
\end{tabular}

Remark: the time lag interval corresponding to the maximum correlation is given in brackets

2. Soil RERs and concentrations in the points FR and FL have a very weak correlation with the corresponding parameters in the point $\mathrm{W}$ (i.e. the behavior of radon at point $\mathrm{W}$ is different), since the inlet is located above the soil level (Fig. 1). In addition, the RER from the point $\mathrm{W}$ is significantly lower than the soil RER from the floor's points (see Section 3). Therefore, the contribution of the soil radon from behind the wall in the ER1 to the behavior of indoor radon can be neglected. That is why further discussion is focused only on the points FR and FL. In addition, a moderate correlation is observed between indoor radon concentration in ER1 and radon concentration in point $\mathrm{W}$ representing the indoor radon in the space behind the wall. This finding reveals a similarity of the indoor radon behavior in the experimental room and in the space behind the wall.
3. The soil radon concentration in the points FR and FL has a moderate or strong correlation with outdoor temperature (inverse relationship), atmospheric pressure (direct relationship), air humidity (inverse relationship), and tidal forces (direct relationship). At the same time, the soil RER from the points FR and FL has a weak correlation (or has even no correlation) with the weather factors, as well as with tidal forces and earthquakes. This means that it is impossible, in principle, to develop a mathematical model to take into account the influence of even one of the considered factors on the soil RER into building by convection of soil gas.

4. The average concentration of soil radon under the building foundation in winter $\left(67 \mathrm{kBq} \mathrm{m}^{-3}\right)$ is higher than in summer $\left(40 \mathrm{kBq} \mathrm{m}^{-3}\right)$, while the maximum relative difference between the measured values is 

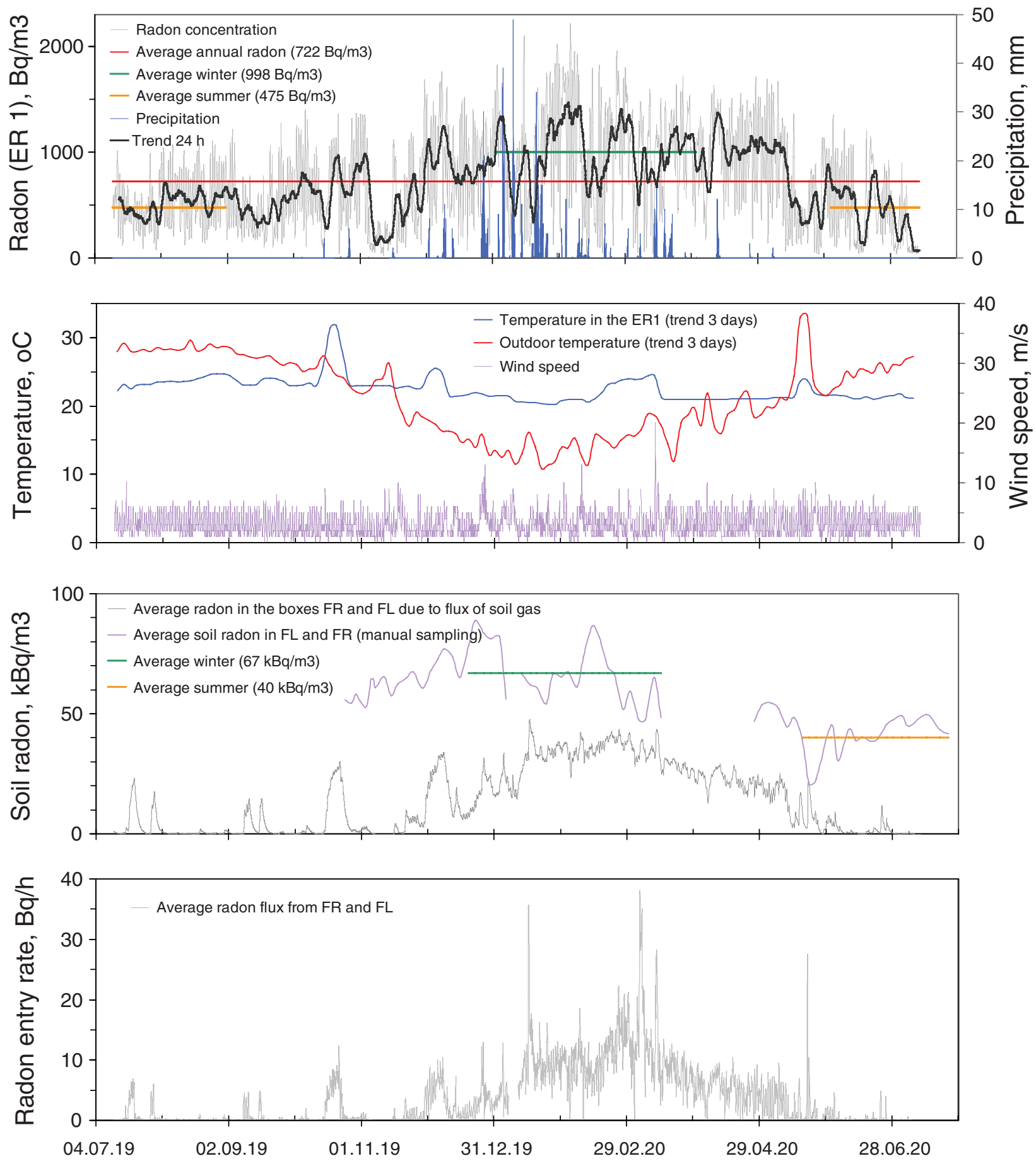

Fig. 6. The results of the annual monitoring of indoor and soil radon, main environmental factors, and the calculation of time series of RER.

$5.3\left(92.7 \mathrm{kBq} \mathrm{m}^{-3}\right.$ in winter and $17.6 \mathrm{kBq} \mathrm{m}^{-3}$ in summer). The relatively high concentration of soil radon in the winter season can be explained by a decrease in the volume of the gas phase in the pore space of the soil due to the soil moistening with rainwater.
It is known that radon has relatively low solubility in water (Ostwald coefficient is about 0.23 at $25^{\circ} \mathrm{C}$ and decreases with the temperature), and therefore, increase of the soil moisture and temperature results in the increase of radon concentration in the soil 
pores - in those pores which are unfilled with water (18), although the total radon activity in the soil (socalled bulk activity concentration) does not change. The process of water saturation and redistribution in the soil is long and uneven in both time and space. Apparently, the calculation of the correlation coefficient between soil radon concentration and precipitation yielded a low value. Besides, an additional soil radon activity could migrate from the deep soil layers with higher radon concentrations when soil gas convective transport is set or increases in winter. It should be noted here that during the sharp and prolonged (over several days) increase in outdoor temperatures on 17 May 2020, a sharp decrease in the concentration of both soil and indoor radon, and at the same time a sharp increase in the RER, was observed (Fig. 6).

5. The soil radon entry due to convection starts to form and shows a rather stable growth approximately since the middle of November, when the daily outdoor temperatures become lower than the indoor temperatures. As long as the difference between the temperatures increases, the RER continues to grow up reaching the maximum approximately at the end of February - up to the middle of March. Then, in parallel to the decrease of the temperature difference between indoors and outdoors rather stable decrease of the RER till almost zero - at the moment when the daily temperature outdoors become higher than those indoors, is observed. It happens approximately in the end of May. By the way, both events, when the temperature difference changed the sign to the opposite one (in mid-November and end of May), almost coincided with the sharp growth of outdoor temperature and the sharp drop of the indoor radon concentration.

The stable convective transport of soil radon is, however, observed for about 6 months a year during the winter and spring seasons, which corresponds to the period of maximum indoor radon concentration (about $1,000 \mathrm{~Bq} \mathrm{~m}^{-3}$ ). During the remaining 6 months, there is no convective transfer of soil radon, with the exception of single, but relatively intense radon entry by convection, the duration of which is not longer than 4 days. However, these sporadic events do not significantly increase indoor radon concentration. Moreover, during the summer and autumn seasons, when there is no convective transport of soil radon, a relatively high level of indoor radon is still observed with an average value of about $500 \mathrm{~Bq} \mathrm{~m}^{-3}$. Thus, it can be concluded that a sufficiently high level of indoor radon during the summer and autumn seasons is created only due to the diffusion of soil radon into the experimental room.
It should be clarified that until now the term (parameter) 'soil radon entry rate' was referred to the rate of radon release only due to convection from specific holes (with a diameter of $4 \mathrm{~mm}$ ) artificially created by drilling in the floor and wall of the experimental room. Therefore, sometimes a more precise wording was used in the text as 'soil radon entry rate from the FR point'. However, for the use in the indoor radon balance equation (5), 'soil radon entry rate' only refers to the soil radon, which penetrated through the foundation slab (not only due to convection but also due to diffusion) and released from the corresponding area into the room. Since one of the considered parameters does not take into account the diffusion mechanism, the relationship of these parameters cannot have a universal mathematical expression, even when the resistance of the floor slab to the transport of soil radon into the room is zero (i.e. an open soil surface serves as a room floor). Nevertheless, the data presented above quite adequately reflect the nature of temporal variations, as well as the potential of the soil radon entry due to the soil gas convection only. Obviously, the effect of this potential will decrease with increasing resistance of the building structure to the flow of soil radon into the room.

Thus, the proposed experimental scheme and mathematical apparatus make it possible to qualitatively assess the nature of temporal variations in soil RER, as well as the role of soil gas convection in the mechanism of soil radon transport inside the building.

In view of the above, especially mentioned in item 5), the statement that convection is the main mechanism responsible for the transport of soil radon into buildings with an elevated radon concentrations cannot be considered correct. This opinion us shared by the radon standards of the ISO 11665 series (19) mentioning that both these radon transport mechanisms can take a place, while the convective transport is not distinguished as the main one. In addition, it should be borne in mind that unlike convection, the diffusion of soil radon into the building is a regular (constant in time) process, which is due to the always existing concentration gradient between soil and indoor radon (19), the values of which usually differ by more than two orders of magnitude. Therefore, the characterization of the mechanisms of transport of soil radon into the building will look more correct if we say that the main mechanism of transport of radon into the building is diffusion, which can sometimes be enhanced by convection of soil gas.

\section{Conclusions}

1. A simple experimental scheme and mathematical apparatus to study the concentration behavior and 
mechanism of soil radon transport from beneath a building foundation are proposed.

2. The long time series of continuous measurements are reported for the following:

- indoor radon with a high concentration in the experimental room located in the building basement;

- soil radon concentration and RER into the experimental room through the artificial holes in the floor and wall;

- climatic and other factors influencing the behavior of soil and indoor radon;

3. Comparative analysis of the obtained time series, including the assessment of the correlation between them, led to the following main conclusions:

- A spatial similarity of the soil radon behavior beneath the building foundation slab within the 31 $\mathrm{m}^{2}$ area of the experimental room was observed.

- similar character of temporal variations of indoor radon in the experimental room of the basement and in the neighboring space behind the wall.

- It is impossible, in principle, to develop a mathematical model to take into account the influence of factors, such as weather conditions, tidal forces, and earthquakes, on the soil RER into building by convection of soil gas;

- The soil radon concentration beneath the building foundation slab has temporal variations, including seasonal fluctuations (40 and $67 \mathrm{kBq} \mathrm{m}^{-3}$ in summer and in winter, respectively), which can be explained mainly by significant moistening of the soil in winter due to heavy rainfalls.

- There is absence of soil radon entry by only convection mechanism into the experimental room for the summer and autumn seasons; however, indoor radon concentration remains high (about $500 \mathrm{~Bq} \mathrm{~m}^{-3}$ ) due to the diffusion of soil radon; a regular soil radon entry into the experimental room by convection is observed in the winter and spring seasons with a maximum achieved approximately at the beginning of the spring season; therefore, indoor radon concentration is twice as high as in the summer and autumn seasons.

4. The results obtained indicate that not only convective mechanism but also diffusion plays a significant role in the transport of soil radon in the formation of indoor radon.

\section{Acknowledgments}

\section{Conflict of interest and funding}

The authors declare that there is no conflict of interest. This research project has received funding from the
European Union's Horizon 2020 research and innovation programme H2020-MSCA-IF-2017 under Grant agreement No. 792789 (RadonACCURACY).

\section{References}

1. UNSCEAR (United Nations Scientific Committee on the Effects of Atomic Radiation). Sources and effects of ionizing radiation. Vol. 1, Annex B. New York: United Nations; 2008, p. 463.

2. WHO. Handbook on indoor radon: a public health perspective. Geneva: World Health Organization; 2009. ISBN 978-92-4-154767-3.

3. WHO. Housing and health guidelines. Geneva: World Health Organization; 2018. ISBN 978-92-4-155037-6.

4. Council Directive 2013/59/Euratom, Laying down basic safety standards for protection against the dangers arising from exposure to ionizing radiation and repealing directives $89 / 618$, 90/641, 96/29, 97/43 and 2003/122/Euroatom, Official Journal of the European Union, L13, 17 January 2014. Available from: https://eur-lex.europa.eu/LexUriServ/LexUriServ.do?uri=OJ:L:2014:013:0001:0073:EN:PDF [cited 28 September 2021]

5. Schroeyers W. (Ed.). Naturally occurring radioactive materials in construction. Cambridge, MA: Elsevier Ltd.; 2017, p. 320. ISBN 978-0-08-102009-8.

6. Marennyy A. (Ed.). Comprehensive monitoring studies of radon in soil. Sunnyvale, CA: Sunnyvale, CA: LAP Lambert Academic Publishing; 2019, 216 pp. ISBN 978-6-139-87366-1.

7. EN 16798-1, Energy performance of buildings - Ventilation for buildings, Part 1: indoor environmental input parameters for design and assessment of energy performance of buildings addressing indoor air quality, thermal environment, lighting and acoustics module M1-6. CEN (European Committee for Standardization); 2019. ISBN 978-0-580-85868-0. Sunnyvale, CA 94085, USA.

8. Gulabyants L, Livshits M, Kalaydo A, Kovler K. Resistance of building foundation to radon penetration. J Build Phys 2020; 43(5): 456-73. doi: 10.1177/1744259119844533

9. Cliff K.D. and Miles J.C.H. (Eds.). Radon Research in the European Union. EUR-17628. Chilton: National Radiological Protection Board; 1997.

10. Naturally occurring radiation in the Nordic countries - recommendations, 2000. The radiation protection authorities in Denmark, Finland, Iceland, Norway and Sweden. 80 pp. ISBN 91-8923000-0. Available from: https://www.gr.is/wp-content/media/2013/07/ NaturallyOccurringRadioactivity.pdf [cited 28 September 2021]

11. Nazaroff W, Nero A. (Ed.). Radon and its decay products in indoor air. Jr. New York, NY: John Wiley \& Sons, Inc.; 1988. ISBN 0-471-62810-7.

12. ISO 12569:2017. Thermal performance of buildings and materials - determination of specific airflow rate in buildings - tracer gas dilution method. 2017, pp. 1-53. Available from: https:// www.iso.org/standard/74661.html [cited 28 September 2021]

13. ASTM E741-11. Standard test method for determining air change in a single zone by means of a tracer gas dilution. 2017, pp. 1-17. Available from: https://www.astm.org/Standards/ E741.htm

14. Andersen C. Entry of soil gas and radon into houses. RisoR-623(EN). Roskilde: Risø National Laboratory; 1992. ISBN 87-550-1804-1.

15. Revzan K, Fisk W. Modelling radon entry into houses with basements: the influence of structural factors. Indoor Air 1992; 2(1): 40-8. doi: 10.1111/j.1600-0668.1992.05-21.x

16. Marennyy A, Tsapalov A, Miklyaev P, Petrova T. Laws of the formation of radon field in a geological medium. 
Moscow: Publisher 'Pero'; 2016, 394 pp. (in Russian) ISBN 978-5-906883-94-0.

17. Tsapalov A, Kovler K, Shpak M, Shafir E, Golumbic Y, Peri A, et al. Involving schoolchildren in radon surveys by means of the 'RadonTest' online system. J Environ Radioact 2020; 217: 106215. doi: 10.1016/j.jenvrad.2020.106215

18. UNSCEAR (United Nations Scientific Committee on the Effects of Atomic Radiation). Sources and effects of ionizing radiation. Vol. 1, Annex B. New York: United Nations; 2000, p. 654 .

19. ISO11665-1:2019. Measurement of radioactivity in the environment - air: radon-222 - part 1: origins of radon and its short-lived decay products and associated measurement methods. Available from: https://www.iso.org/standard/76006.html [cited 28 September 2021]

\section{*Konstantin Kovler}

National Building Research Institute,

Faculty of Civil and Environmental Engineering

Technion - Israel Institute of Technology,

Haifa 3200003,

Israel

Email: cvrkost@technion.ac.il 